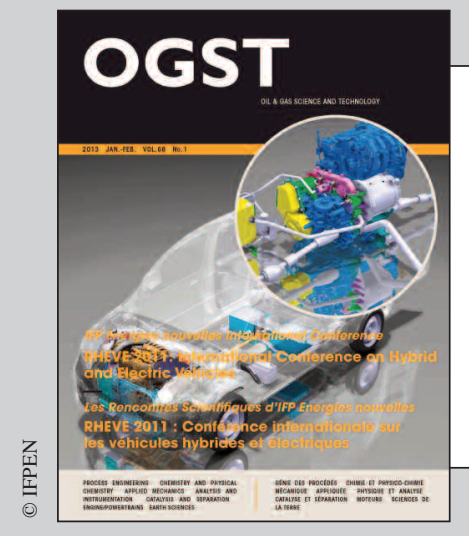

Dossier

This paper is a part of the hereunder thematic dossier published in OGST Journal, Vol. 68, No. 1, pp. 3-178 and available online here

Cet article fait partie du dossier thématique ci-dessous publié dans la revue OGST, Vol. 68, n 1 , pp. 3-178 et téléchargeable ici

DOSSIER Edited by/Sous la direction de : A. Sciarretta, F. Badin et J. Bernard RHEVE 2011 : International Conference on Hybrid and Electric Vehicles RHEVE 2011 : Conférence internationale sur les véhicules hybrides et électriques

Oil \& Gas Science and Technology - Rev. IFP Energies nouvelles, Vol. 68 (2013), No. 1, pp. 3-178

Copyright (C) 2013, IFP Energies nouvelles

\section{$3>$ Editorial}

$13>$ Analysis and Experimental Implementation of a Heuristic Strategy for Onboard Energy Management of a Hybrid Solar Vehicle

Analyse et expérimentation d'une stratégie heuristique pour la gestion d'énergie à bord d'un véhicule hybride solaire

G. Coraggio, C. Pisanti, G. Rizzo and M. Sorrentino

23 > Open Issues in Supervisory Control of Hybrid Electric Vehicles: A Unified Approach Using Optimal Control Methods

Questions ouvertes sur la supervision énergétique des véhicules hybrides électriques : une approche unifiée par la théorie de la commande optimale

L. Serrao, A. Sciarretta, 0. Grondin, A. Chasse, Y. Creff, D. Di Domenico, P. Pognant-Gros, C. Querel and L. Thibault

35 > Optimization of Hybrid Power Trains by Mechanistic System Simulations

Optimisation de groupes motopropulseurs électriques hybrides par simulation du système mécanique

T. Katrašnik and J.C. Wurzenberger

51 > A Phenomenological Heat Transfer Model of SI Engines - Application to the Simulation of a Full-Hybrid Vehicle

Un modèle phénoménologique de transfert thermique au sein de moteurs à allumage commandé - Application à la simulation d'un véhicule full-hybride

R. Dubouil, J.-F. Hetet and A. Maiboom

$65>$ Battery Electric Vehicle (BEV) or Range Extended Electric Vehicle (REEV)? - Deciding Between Different Alternative Drives Based on Measured Individual Operational Profiles

Véhicule électrique à batteries (BEV) ou véhicule électrique à prolongateur d'autonomie (REEV) ? - Choisir entre différents entrânements alternatifs sur la base de profils opérationnels individuels mesurés

S. Marker, B. Rippel, P. Waldowski, A. Schulz and V. Schindler

$79>$ Assessment by Simulation of Benefi ts of New HEV Powertrain Configurations

Évaluation par simulation des bénéfi ces de nouvelles chaînes de traction hybrides

N. Kim and A. Rousseau
95 > Dual Mode Vehicle with In-Wheel Motor: Regenerative Braking Optimization

Véhicule bi-mode avec moteurs roues : optimisation du freinage récupératif

G. Le Solliec, A. Chasse, J. Van-Frank and D. Walser

109 > Engine Downsizing and Electric Hybridization Under Consideration of Cost and Drivability

Réduction de taille moteur et hybridation électrique avec considérations de coût et de performance de conduite

S. Ebbesen, P. Elbert and L. Guzzella

117 > Representative Midwestern US Cycles: Synthesis and Applications Cycles représentatifs du Middle West américain : synthèse et applications

T.-K. Lee and Z.S. Filipi

127 > A Review of Approaches for the Design of Li-lon BMS Estimation Functions

Revue de différentes approches pour l'estimation de l'état de charge de batteries Li-ion

D. Di Domenico, Y. Creff, E. Prada, P. Duchêne, J. Bernard and V. Sauvant-Moynot

137 > Experimental Assessment of Battery Cycle Life Within the SIMSTOCK Research Program

Évaluation expérimentale de la durée de vie de la batterie dans le programme de recherche SIMSTOCK

P. Gyan, P. Aubret, J. Hafsaoui, F. Sellier, S. Bourlot, S. Zinola and F. Badin

$149>$ Smart Battery Thermal Management for PHEV Efficiency Une gestion avancée de la thermique de la batterie basse tension de traction pour optimiser l'efficacité d'un véhicule hybride électrique rechargeable

L. Lefebvre

$165>$ Parameterization and Observability Analysis of Scalable Battery Clusters for Onboard Thermal Management

Paramétrage et analyse d'observabilité de clusters de batteries de taille variable pour une gestion thermique embarquée

Xinfan Lin, Huan Fu, Hector E. Perez, Jason B. Siege, Anna G. Stefanopoulou, Yi Ding and Matthew P. Castanier 


\title{
Experimental Assessment of Battery Cycle Life Within the SIMSTOCK Research Program
}

\author{
P. Gyan ${ }^{1 *}$, P. Aubret ${ }^{2}$, J. Hafsaoui ${ }^{2}$, F. Sellier ${ }^{2}$, S. Bourlot ${ }^{3}$, S. Zinola ${ }^{4}$ and F. Badin ${ }^{4}$ \\ ${ }^{1}$ Renault, 1 Avenue du Golf, TCR LAB 0 12, 78288 Guyancourt - France \\ ${ }^{2}$ LMS Imagine, Cité internationale, 84 quai Charles de Gaulle, 69006 Lyon - France \\ ${ }^{3}$ SAFT, 111 1-1 13 boulevard Alfred Daney, 33074 Bordeaux Cedex \\ ${ }^{4}$ IFP Energies nouvelles - Rond-point de l'échangeur de Solaize, BP 3, 69360 Solaize - France \\ e-mail: philippe.gyan@renault.com - philippe.aubret@Imsintl.com - julien.hafsaovi@lmsintl.com - franck.sellier@lmsintl.com \\ sandrine.bourlot@saftbatteries.com - stephane.zinola@ifpen.fr - francois.badin@ifpen.fr \\ * Corresponding author
}

\begin{abstract}
Résumé - Évaluation expérimentale de la durée de vie de la batterie dans le programme de recherche SIMSTOCK - La stabilité dans le temps des performances des systèmes embarqués de stockage d'énergie (Energy Storage Systems, ESS) est un enjeu majeur pour une diffusion massive et le succès des véhicules électrifiés, hybrides et électriques. L'affaiblissement de la capacité et l'augmentation de la résistance interne due au vieillissement affecteront directement l'autonomie du véhicule et ses performances. Par conséquent, la prévision du vieillissement des ESS reste un domaine important de recherche. Atteindre cet objectif implique des recherches fondamentales sur les matériaux, l'expérimentation, la simulation et la conception. Ce papier décrit les principaux résultats du programme de recherche collaboratif SIMSTOCK qui s'est déroulé pendant 3,5 années avec un budget de 4,2 $\mathrm{M} €$ et qui s'est terminé à l'automne 2011. Ce programme a impliqué 15 partenaires parmi lesquels, des laboratoires de recherche, des fabricants d'ESS, des fournisseurs de composants de véhicules et des constructeurs automobiles et il a bénéficié du soutien de l'ADEME.

Cet article se concentre principalement sur la modélisation et la simulation d'une cellule lithium-ion haute puissance testée dans ce programme. En premier lieu, est décrit l'élaboration d'un modèle numérique de circuit électrique équivalent de la batterie, associé à un outil de calibration et à sa validation expérimentale. En second, sont présentées la construction d'un plan d'expériences, son utilisation et sa validation, pour la définition des expressions mathématiques représentant les évolutions des paramètres du modèle de batterie en fonction du vieillissement de la batterie. Ensuite le papier détaille la méthode mathématique créée dans le but de prendre en compte le cycle et les effets calendaires sur les caractéristiques de la batterie lors des expériences sur bancs. Enfin, le modèle de batterie est intégré dans un modèle complet du véhicule hybride dans la plateforme de simulation Imagine Lab AMESim, afin de déterminer, avec des conditions de conduite réalistes, l'impact du vieillissement de la batterie sur la performance du véhicule et la consommation de carburant.
\end{abstract}

Abstract - Experimental Assessment of Battery Cycle Life Within the SIMSTOCK Research Program - The steadiness over time, of on-board Energy Storage Systems (ESS) performances is a major issue for a successful and massive diffusion of electrified, hybrid and electric vehicles. 
Capacity fade and internal resistance increase due to ageing will directly affect vehicle range and performances. Therefore, ESS ageing forecasting remains an important area of investigations. Reaching this goal involves fundamental research on materials, experimentation, simulation and design by the end users. This paper describes the main results of a 3.5-year, $4.2 \mathrm{M€}$ collaborative research program on battery ageing, SIMSTOCK, which was finished in fall 2011. This program has involved 15 partners among which, research labs, ESS manufacturers, automotive components suppliers and vehicle manufacturers, with the support of the French agency ADEME.

This paper will then focus mainly on modeling and simulation of a lithium-ion high power cell tested within the program. First, it describes the development of a numerical equivalent electrical circuit model of battery, associated with a calibration tool and its experimental validation. Secondly, it describes the construction of a Design of Experiments (DOE), its use and validation, for defining mathematical expressions, representing the battery model parameters evolutions, as a function of battery ageing. Thirdly, the paper details a mathematical method created with the aim to take into account the cycling and the calendar effects on battery characteristics during the experiment on tests benches. Finally, the battery model is integrated in a full hybrid vehicle model, on Imagine Lab AMESim simulation platform, to determine, with realistic driving conditions, the impact of battery ageing on the vehicle performance and fuel consumption.

\section{NOMENCLATURE}

$U$

$I$

$T$

OCV Open Circuit Voltage (V)

$\eta_{C T} \quad$ Charge transfer voltage $(\mathrm{V})$

$\eta_{\text {diff }}$ Diffusion voltage (V)

$\eta_{\Omega} \quad$ Ohmic losses voltage $(\mathrm{V})$

$\eta_{\text {tot }} \quad$ Total voltage drop (V)

$n \quad$ Number of RC circuits representing diffusion

$R c \quad$ Charge resistance $(\Omega)$

$R d \quad$ Discharge resistance $(\Omega)$

$d t c \quad$ Diffusion time constant (s)

$d s s r \quad$ Diffusion steady state resistance $(\Omega)$

SOC State of Charge (-)

$Q \quad$ Battery capacity (A.h)

$Q_{\text {active }}$ Battery capacity limited by active material structure degradation (A.h)

$Q_{\text {Li }} \quad$ Battery capacity limited by lithium losses (A.h)

$X_{1} \quad$ Relative value of the parameter "current" in the testing condition (-)

$X_{2} \quad$ Relative value of the parameter "temperature" in the testing condition (-)

$X_{3} \quad$ Relative value of the parameter "Ah throughput" in the testing condition (-)

$X_{4} \quad$ Relative value of the parameter "SOC variation" in the testing condition (-)

min Minimal relative value of a parameter of a testing condition (-)
MAX Maximal relative value of a parameter of a testing condition (-)

$a_{\mathrm{ij}} \quad$ Numerical coefficient (-)

$k \quad$ Index of the testing condition (-)

Id Discharge current for the testing condition (A)

Temp Temperature for the testing condition $\left({ }^{\circ} \mathrm{C}\right)$

$C T$ Charge throughput for the testing condition (As)

dSOC SOC variation for the testing condition (\%)

\section{INTRODUCTION}

Car manufacturers and tier one suppliers are unveiling more and more optimized vehicles which combine very low Green House Gases (GHG) emissions together with performances in dynamic and range which are equivalent to those of conventional ones. These vehicles rely on internal combustion engines and electricity, implementing different types of hybridization architectures.

These hybrid vehicles, however, share a common limitation regarding the performances of their embedded Energy Storage Systems (ESS) and especially the way their performances may be degraded during vehicle ageing.

Consequently, numerous research programs have been set up worldwide with the aim to analyze the ageing mechanisms, highlight their main parameters and effects and set up proper test procedures [1-8]. These research programs have enabled the scientists to better understand and forecast battery ageing phenomena for automotive applications. 


\section{DESCRIPTION OF THE PROGRAMS}

Within the French context, cars manufacturers, suppliers and research labs have joined their efforts to set up a complete research program dedicated to ESS ageing with the following goals:

- create a set of validated and updated simulation modules for Hybrid Electric Vehicles (HEV) applications;

- take into account the ageing effects in the cell simulation;

- include these modules in a system level simulation model, able to forecast the cell ageing and translate it into a vehicle behavior.

A cost-shared research program SIMSTOCK has been set up with the following partners:

- research labs involved in ageing mechanism understanding, simulation and ageing test realization (CEA Grenoble and Chambéry, EIGSI La Rochelle, IFSTTAR Lyon and Paris, IMS Bordeaux, LEC Compiègne, LRCS Amiens);

- Energy Storage Systems manufacturers (SAFT and $B A T S C A P$ ) who provide the cells to be tested and participate in the interpretation of ageing mechanisms;

- LMS, an industrial partner in charge of the realization, the diffusion and the support of energy storage system simulation modules in the automotive industry;

- vehicle manufacturers (PSA Peugeot Citroën and Renault), other suppliers (Valeo), energy providers $(E D F)$ and labs (IFPEN) as end users of the program;

- the Mobility and Advanced Transportation (MTA) test platform ensuring the coordination of this complex project with 16 partners.

The SIMSTOCK program, which has been carried out between 2007 and mid 2011, focused on cycling ageing phenomena for HEVs high power batteries and supercapacitors $[9,10]$. The project relied on an extremely strong experimental work: 21 battery bench test systems spread among partners were running in parallel for testing three Li-Ion technologies, one Ni-MH and also 3 supercapacitor technologies, representing a cumulated testing time over 160 months. The characterization methods used were capacity measurement, Electrochemical Impedance Spectroscopy (EIS) and time response to pulse profiles. In parallel, a second project SIMCAL has been launched in 2009, involving the same partners with the aim to study, to model and to understand the calendar ageing mechanisms, in a complementary approach $[11,12]$.

Several papers have already been released, describing the two projects, the present paper will focus on the battery simulation, on the methods implemented to set up the different equations of battery ageing together with an example of a vehicle simulation case.

The battery studied in this application is a $5.3 \mathrm{Ah}$ lithium-ion battery with $\mathrm{LiMn}_{2} \mathrm{O}_{4}$ positive electrode and carbon based negative electrode.

\section{BATTERY MODEL AND ASSISTANT TOOL PRESENTATION}

\subsection{Theory Associated to the Simulation of Battery}

The numerical model, developed in the frame of SIMSTOCK program, has to be able to calculate the dynamical voltage response $(U)$ of the battery as a function of input current $(I)$ and temperature $(T)$. The first parameter to be taken into account in a battery model is its Open Circuit Voltage (noted $O C V$ ), which represents the voltage of the battery at its thermodynamical equilibrium. Then, the voltage drops, known as overpotentials or overvoltages, caused by the charge transfer (noted $\eta_{C T}$ ), the diffusion (noted $\eta_{\text {diff }}$ ) and the ohmic losses (noted $\eta_{\Omega}$ ) have also to be considered. Consequently, the formula used in the present model to determine the voltage of the battery can be written as follows:

$$
U=O C V-\eta_{t o t}=O C V-\eta_{C T}-\eta_{\text {diff }}-\eta_{\Omega}
$$

\subsection{Battery Electrochemical Model}

The behavioral model, proposed in this paper, uses the approach of equivalent electrical circuits to simulate the different physical phenomena previously mentioned. The circuit is represented in Figure 1.

In this scheme, the charge transfer is represented by a parallel RC circuit (A: red frame). It is noted that this phenomenon can be neglected for most temporal simulation applications. The $O C V$ is represented by the voltage source (B: cyan frame). The ohmic losses are predicted with the two resistances in parallel (D: blue frame). The presence of anti-parallel diodes makes it possible to use different values of resistance, according to the current direction. Finally, the diffusion is simulated by the serial association of " $n$ " serial RC parallel circuits (C: green frame).

Several parameters therefore have to be filled in to run a simulation with this numerical model, starting with the $O C V$, the charge and the discharge resistances values (noted respectively $R c$ and $R d$ ). In order to determine the number " $n$ " of the RC circuits, it has been considered 


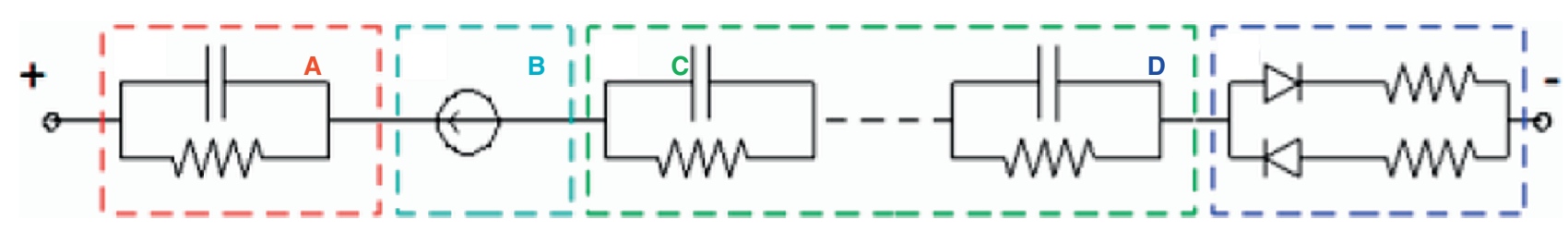

Figure 1

Battery equivalent electrical circuit.

that HEV dynamic usage does not need the longest time constant RC circuits. Measurement acquisition rate makes the shortest time constant components irrelevant for the study. Altogether, a well-chosen single time constant circuit is appropriate for a broad scope HEV battery aging study. Consequently, it is possible to limit the number of parameters characterizing the diffusion behaviour [13]. The parameters of each of the " $n$ " serial $\mathrm{RC}$ circuits representing the diffusion can also be derived from an initial set of parameters and " $n$ ".

Thus, only two parameters need to be determined to perform a temporal simulation of this phenomenon: the diffusion time constant (noted $d t c$ ) and the diffusion steady state resistance (noted $d s s r$ ) [14].

\subsection{Parameterization Assistant Tool}

Obtaining those various parameters to implement the present numerical battery model is complex. Moreover, they could present some dependencies on SOC, temperature $(T)$ and possibly current $(I)$. In this context, a parameter identification assistant tool associated with this numerical model has been developed, in order to determine the different parameters and their dependencies.

This assistant tool requires as input data from measurements the input current applied to the battery and the corresponding voltage response. These experimental characterizations have to be recorded under a large range of SOC and current at different temperatures. Then, under those various conditions, every model parameter necessary for the implementation of a temporal simulation ( $O C V, R c, R d, d t c$ and $d s s r)$ is computed by the parameterization assistant tool. The principles of this identification are described in [14, 15]. The data output is in the form of $2 \mathrm{D}$ and $3 \mathrm{D}$ table files representing, respectively, the $O C V$, ohmic resistances and diffusion parameters, with their dependencies on SOC and $I$ at a given temperature. These parameter files are stored in a format directly readable by the LMS Imagine Lab AMESim platform.

\section{BATTERY AGEING FOLLOW UP}

In the frame of SIMSTOCK program, batteries are tested experimentally in order to follow the evolution of their behavior according to specific ageing conditions. A protocol is used at the beginning of life and then at regular period of time in order to monitor battery performances (capacity decrease and impedance increase). This characterization protocol consists in a capacity measurement of each cell, an Electrochemical Impedance Spectroscopy (EIS) and the voltage response to current pulses at different SOC. Thus, for given ageing conditions, the voltage response of a battery to this current pulses profile, can be represented as in Figure 2.

The parameterization assistant can be used to perform identification for each of the previous protocols in order to obtain the evolution of the different parameters $(O C V, R c, R d, d t c$ and $d s s r)$ of the numerical model as a function of SOC, current and battery's ageing time.

Finally, at the end of all ageing cycles and characterization protocols, a database for all parameters $(O C V$,

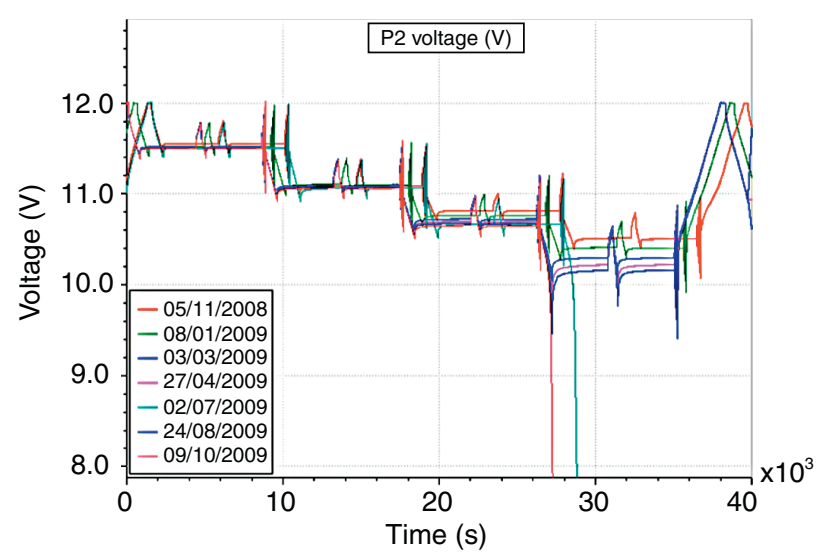

Figure 2

Voltage response of a Li-ion battery at different times during its ageing in cycling $\left(T: 50^{\circ} \mathrm{C} ; \triangle S O C: 40 \% ; I d: 130 \mathrm{~A}\right.$; CT: $650 \mathrm{As})$ [14]. 
TABLE 1

Testing conditions of the batteries

\begin{tabular}{|c|c|c|c|c|c|c|c|c|c|c|c|}
\hline \#Test & 1 & 2 & 3 & 4 & 5 & 6 & 7 & 8 & 9 & 10 & 11 \\
\hline$I d(\mathrm{~A})$ & MAX & MAX & MAX & MAX & MAX & MAX & $\min$ & $\min$ & $\min$ & $\min$ & $\min$ \\
\hline Temp $\left({ }^{\circ} \mathrm{C}\right)$ & MAX & MAX & MAX & MAX & $\min$ & $\min$ & MAX & MAX & MAX & $\min$ & $\min$ \\
\hline CT (As) & MAX & $\min$ & MAX & $\min$ & $\min$ & MAX & MAX & $\min$ & MAX & MAX & $\min$ \\
\hline$d S O C(\%)$ & MAX & MAX & $\min$ & $\min$ & MAX & $\min$ & MAX & MAX & $\min$ & MAX & $\min$ \\
\hline
\end{tabular}

$R c, R d, d s s r$ and $d t c$ ) of the numerical model will be available. From this database and thanks to the theory of the design of experiment used in SIMSTOCK program it will be possible to determine the ageing laws for each parameter of the model. The numerical model will then be adapted to take the evolution of these parameters into account for given simulation's operating conditions.

\section{EXPRESSION OF CAPACITY AGEING BEHAVIOUR}

\subsection{Representation of the Ageing}

The principle of the exploitation of the measurements is to establish the expression of the measured capacity Q, with respect to the variable $Y$ representing at best the ageing, and the conditions in which the tests were performed. The capacity considered is the "useful" capacity, representative of the SOC range were performances are met (based on some reference duty cycle, etc.). This accounts for both capacity loss and resistance growth in a balanced manner.

The variables representing the ageing can be number of the micro cycles, accumulated Ah, or calendar time.

The tests were performed for different conditions of current, temperature, Ah throughput and SOC variations, respectively designated by $X_{1}, X_{2}, X_{3}, X_{4}$. Each of these parameters has two values (a $\min$ and a $M A X$ ) [9]. The design of experiment established showed that at least 11 different tests were necessary to determine the coefficients of the polynomial expression representing the ageing (Tab. 1).

Initially, this polynomial expression was composed of 11 terms, as a combination of parameters described in:

$$
\begin{aligned}
f(Y)= & y_{00}+y_{01} \cdot X_{1}+y_{02} \cdot X_{2}+y_{03} \cdot X_{3}+y_{04} \cdot X_{4} \\
& +y_{12} \cdot X_{1} \cdot X_{2}+y_{13} \cdot X_{1} \cdot X_{3}+y_{14} \cdot X_{1} \cdot X_{4} \\
& +y_{23} \cdot X_{2} \cdot X_{3}+y_{24} \cdot X_{2} \cdot X_{4}+y_{34} \cdot X_{3} \cdot X_{4}
\end{aligned}
$$

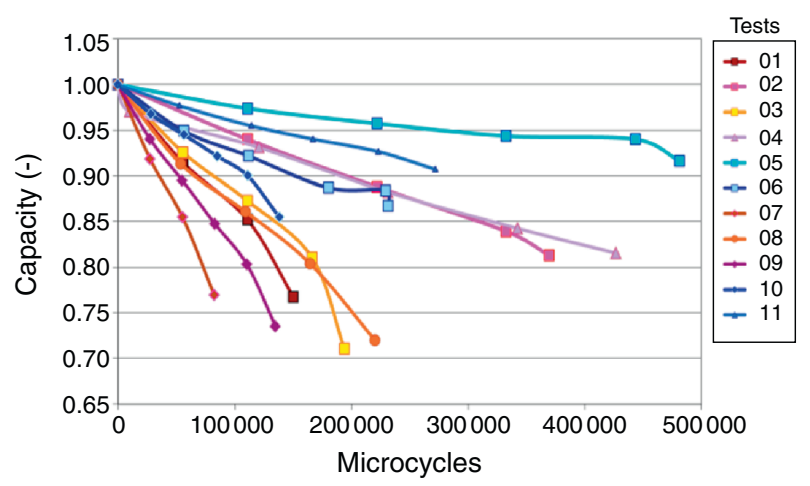

Figure 3

Measured capacity fade versus microcycles.

However, the numerical determination of these 11 coefficients was very sensitive to error, noise, scattering of values within a set of data.

Some of the cross-terms $X_{i} \cdot X_{j}$ did not have any real physical interpretation, and could lead to numerical divergences when extrapolations are performed outside of the experimental domain.

Therefore, this polynomial expression was simplified, by keeping only the main independent terms, in order to have a better numerical robustness:

$$
F(Y)=y_{00}+y_{01} \cdot X_{1}+y_{02} \cdot X_{2}+y_{03} \cdot X_{3}+y_{04} \cdot X_{4}
$$

The microcycles had different duration and $\mathrm{Ah}$ throughput, therefore it was not relevant to consider the number of microcycles as the variable representing the ageing (Fig. 3).

The variable $Y$ representing the ageing was then considered as the cumulated ampere.hours (Fig. 4). However, it was observed that the capacity fade according to cumulated $\mathrm{Ah}$ was greater for a smaller current and Ah throughput (test 01 and test 08 ) which is not the expected behavior. 


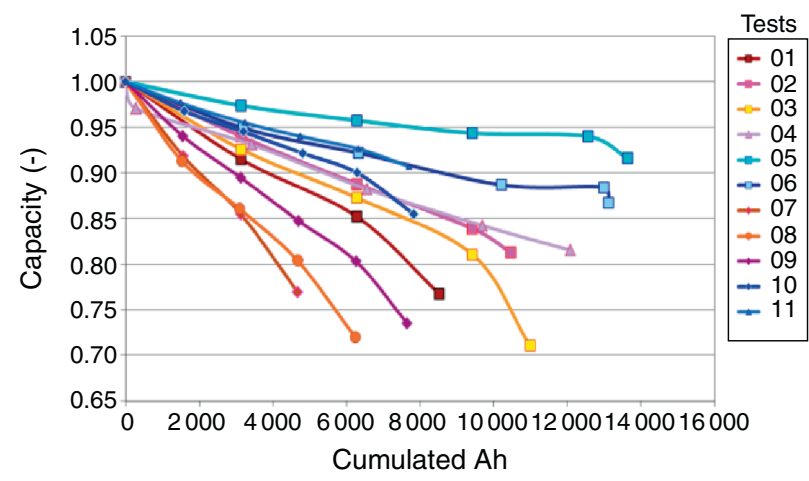

Figure 4

Measured capacity fade versus cumulated Ah.

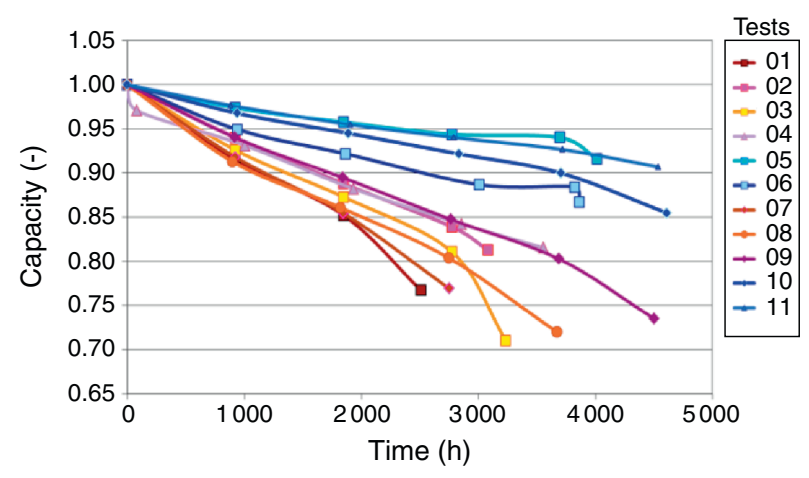

Figure 5

Measured capacity fade versus time.

Battery ageing is usually the consequence of two combined effects: operating conditions (cycling ageing) and also storage conditions (calendar ageing). Therefore, time should be the variable representing the ageing. Indeed, for a given cumulated Ah value, test performed with the lower current lasts more time than the test performed with the higher current. So, when represented on the same time scale, the two capacity fades (test 01 and test 08) become equivalent (Fig. 5). Then, the capacity evolution presents a sharper drop, with a greater fade for the testing condition with the highest current and Ah-throughput, which is the expected behavior. Two distinct phenomenons should be represented in the modeling.

The works of Smith et al. [16] present a description of these two distinct behaviors: they give an expression of capacity fade that includes a time-dependent term corresponding physically to the loss of lithium concentration and another term depending on the number of cycles corresponding to the active material degradation and mechanical fracture (Fig. 6).

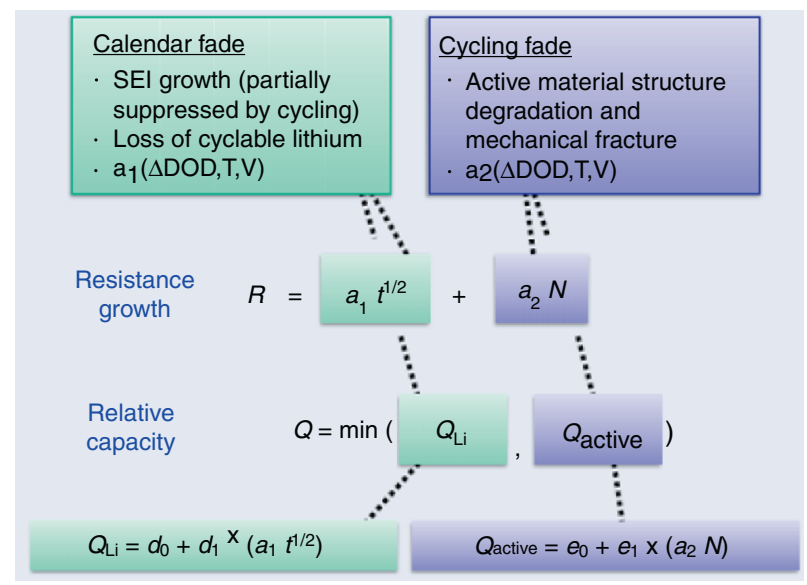

Figure 6

Expressions of resistance and capacity fade.

These two phenomenons are not added; capacity is the minimum of the two of them.

In the approach of NREL, the ageing conditions remain fixed throughout the ageing process. However, in cases of usage scenarios applied to vehicles, the conditions of current, temperature, Ah-throughput and range of SOC will change. It is therefore necessary to take into account these variations, by representing, not directly the capacity, but the capacity variation and calculating the capacity by integration over time.

Thus, a differential approach, taking into account the capacity variation after each elementary solicitation on the battery was adopted in this modeling.

The experimental data of ageing batteries achieved during SIMSTOCK program were not always sufficient to characterize fully the part of the active material structure degradation $Q_{a c t i v e}$ as a function of the number of cycles; this would have required extending the measurements below $70 \%$ of the initial capacity, which was not possible within the project timeframe.

The following part will focus on the representation of the capacity fade due to the lithium losses $Q_{l i}$.

For each test $j$, the equations governing the evolution of capacity are as described in (4):

$$
\begin{gathered}
\left(\frac{d Q_{\mathrm{Li}}}{d(\sqrt{t})}\right)_{j}=a_{j} \text { with } \\
a_{j}=a_{00}+a_{01} \cdot X_{1, j}+a_{02} \cdot X_{2, j}+a_{03} \cdot X_{3, j}+a_{04} \cdot X_{4, j}
\end{gathered}
$$

\subsection{Estimation of the Ageing}

For current, Ah-throughput and SOC variation, the values of the testing parameters $\min$ and $M A X$ are chosen 
TABLE 2

Values of the testing conditions of the batteries

\begin{tabular}{c|c|c}
\hline & Min & MAX \\
\hline$I d(\mathrm{~A})$ & 65 & 130 \\
\hline $\operatorname{Temp}\left({ }^{\circ} \mathrm{C}\right)$ & 40 & 50 \\
\hline $\mathrm{CT}(\mathrm{A} . \mathrm{s})$ & 650 & 1300 \\
\hline $\mathrm{d} S O C(\%)$ & 20 & 40 \\
\hline
\end{tabular}

TABLE 3

Numerical coefficients of the polynomial expression

\begin{tabular}{c|c|c}
\hline$a_{00}$ & 0.0010 & Constant \\
\hline$a_{01}$ & -0.0001 & Current \\
\hline$a_{02}$ & -0.0021 & $\mathrm{~T}^{\circ}$ \\
\hline$a_{03}$ & -0.0009 & $\mathrm{CT}$ \\
\hline$a_{04}$ & -0.0006 & $\mathrm{~d} S O C$ \\
\hline
\end{tabular}

so that $M A X=2 \times \min$. For temperature, it is assumed that under a certain value $T_{0}$, the ageing has little effect. Therefore $T_{M A X}-T_{0}=2\left(T_{\min }-T_{0}\right)(T a b .2)$.

Min and $M A X$ are then expressed in a normalized format within $[0.5,1]$, so that 0 would correspond the absence of value.

The coefficients $a_{00}, a_{01}, a_{02}, a_{03}, a_{04}$ (Tab. 3) are determined by minimizing the error of the estimation over the 11 tests of Table 1.

The analysis of the numerical values shows, for this electrochemistry of batteries, that:

- the predominant effect is temperature;

- the effect of Ah throughput is greater than the one of current;

- without stress, the coefficient $a_{00}$ is positive, the battery will regain capacity at low temperature.

The first results of the model can then reproduce the behaviour of the first part of the experimental measurements as shown in Figure 7. Investigations are still under progress to represent the linear part presented in Figure 6.

It can also represent usage scenarios for which each request for a time increment under the conditions $\left(X_{1}, X_{2}, X_{3}, X_{4}\right)$ contributes to ageing.

The simulation in Figure 8 shows capacity recovery when including rest periods within cycling periods. Similar results have been observed experimentally by Dudezert [17] and by Badey [18] for different cells, when including rest periods within cycling periods. Further

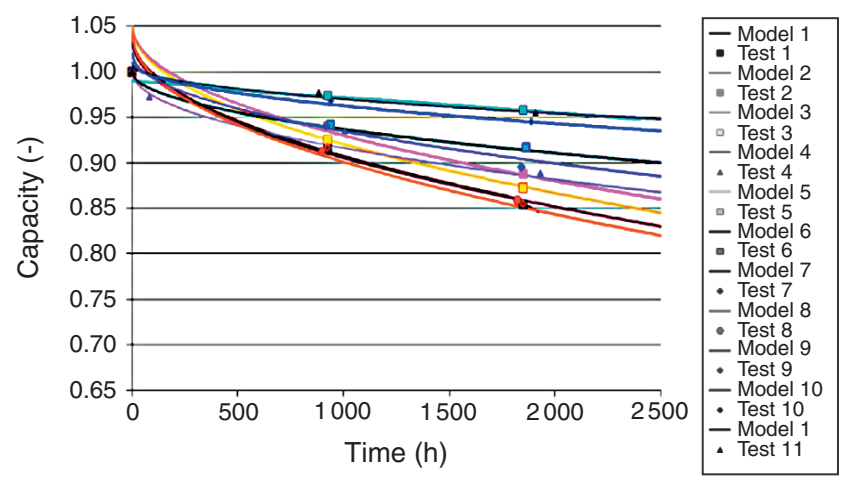

Figure 7

Modeling of capacity fade versus time.

work will investigate more deeply the reproduction of such phenomenon with the model that has been established.

A similar approach has been applied to the capacity measurements in the SIMCAL program, as illustrated in Figure 9, with calendar ageing under different conditions of temperature and state of charge, considering that current and Ah-throughput are equal to zero.

Thus, the modeling approach of the capacity fade in the SIMSTOCK project offers direct compatibility with the results of the SIMCAL Project.

The model gives good results between the values 0 and $M A X$ of each parameter. So far, it cannot be extrapolated below $T_{0}=30^{\circ} \mathrm{C}$.

More of experimental measurements are available within SIMCAL project according to temperature and state of charge. It will allow, in further work, to represent more accurately the dependence of the capacity fade to temperature and SOC, and re-introduce these results into a more comprehensive expression of the capacity fade.

These results then will be applied to the usage scenario of a vehicle.

\section{RESULTS EXPLOITATION}

\subsection{Objective}

As already mentioned, the aim of the SIMSTOCK and SIMCAL projects is to enable the final users, Original Equipment Manufacturers (OEM), suppliers and battery manufacturers to be able to evaluate the ESS behavior during vehicle use. Consequently, the final step is to integrate the results of the measurements exploitation 


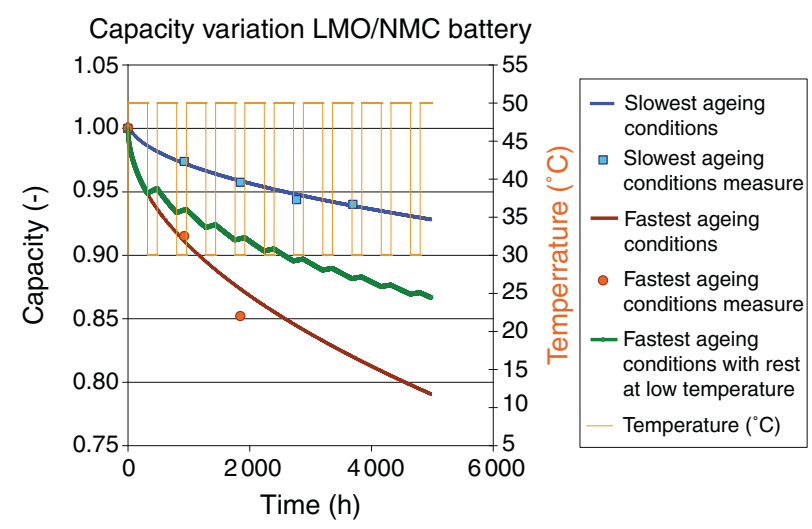

Figure 8

Simulation results representing a succession of stress and rest periods.

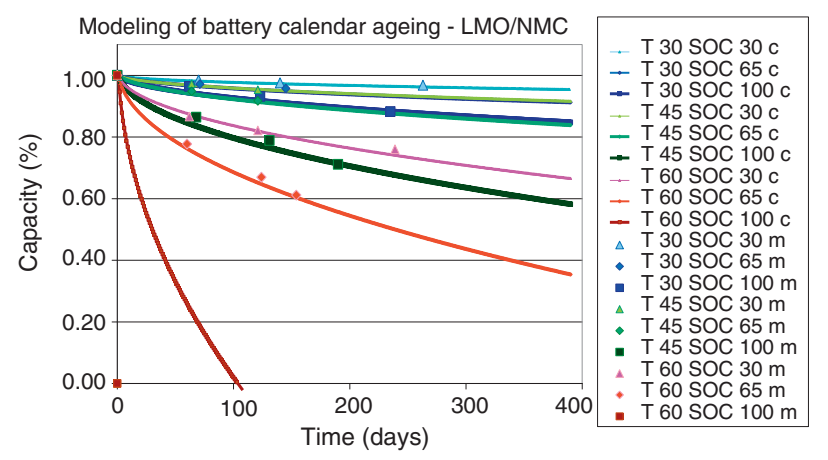

Figure 9

Example of measurement and modeling of capacity fade in the frame of SIMCAL Project (c: calculation, m: measure). described above in a process that will enable to forecast battery pack capacity fade and internal resistance increase throughout the entire vehicle life. When the on-going SIMCAL program will end, the procedure will take into account the combination of cycling and calendar ageing, then corresponding to the actual case in the vehicle. Meanwhile, the procedure described in this paper will consider the results of the cycling tests only, keeping in mind that these results already account for a part of calendar ageing appearing during the cycling tests, as already mentioned.

\subsection{Implementation}

The first step is to establish a simulation scheme of the hybrid vehicle with its components properly sized according to the specification of the vehicle program of demand. The AMESim platform, with the ESS electrochemical model described in Section 3, has been implemented. The HEV considered in our example is a parallel pre-transmission with a $43 \mathrm{~kW}$ high power lithium ion battery enabling full hybrid functionalities and operated in Charge Sustaining (CS) mode.

In a second step, the ESS ageing evaluation is carried out in a loop implementing two major stages (Fig. 10):

- simulation of the vehicle on its specific mission with the aim to determine the ESS constraints together with vehicle fuel economy and dynamic performances with the ESS gradually deteriorated;

- evaluation of the ESS deterioration in capacity and internal resistance, implementing the equation previously described in Section 4.
This loop simulates the entire vehicle life; it will end when the vehicle is no more able to satisfy the requested driving mission. As far as HEV operated in CS mode are concerned, this condition may be more complex than the one defined for the EV case, which is generally a loss in capacity $(20 \%)$ and consequently in range. For this considered case a vehicle dynamic performance criteria is added.

One could note that the simulation loop may take into account seasonal effects impacting ESS ambient temperature and vehicle auxiliaries loads (cabin climate control).

\subsection{Results}

In order to illustrate the program results, the case of a delivery vehicle operating in peri-urban conditions for 6 hours a day and 200 days per year is considered. Figure 11 illustrates the result obtained in capacity fade for the first 3 years of vehicle operation, i.e. an equivalent of $200000 \mathrm{~km}$ covered, according to our hypothesis. Three different cases appear in Figure 11:

- two curves illustrate the response of the model if the minimum and maximum constraints of the planned experiment are applied. One may note on the one hand the influence of these constraints on capacity fade and on the other hand the limited impact, as compared with the accelerated tests illustrated in Figure 8;

- the intermediate curve illustrates the actual simulated use case and it can be noticed that the "close to real life" constraints are not severe as compared to those implemented in our accelerated protocol. 


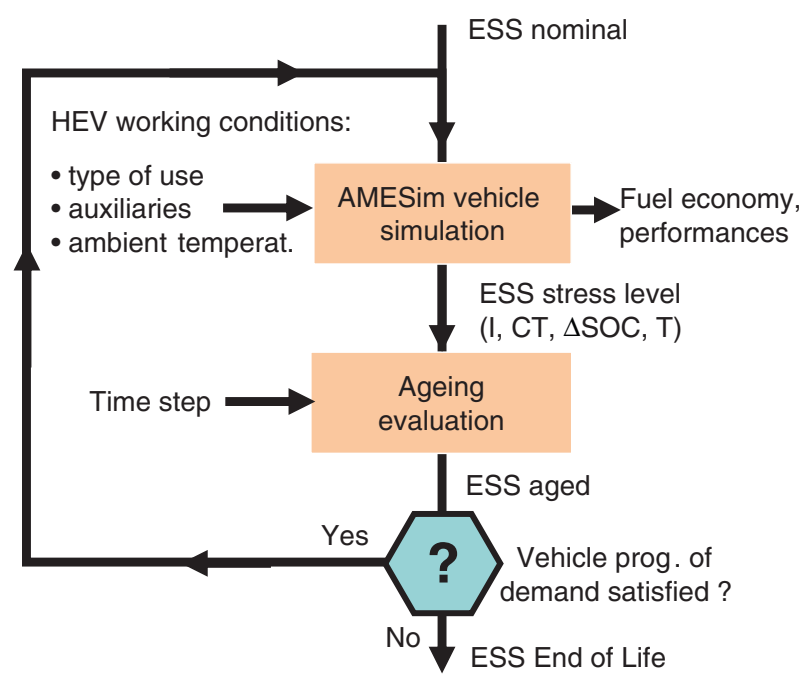

Figure 10

Principle of ESS ageing evaluation on a vehicle.

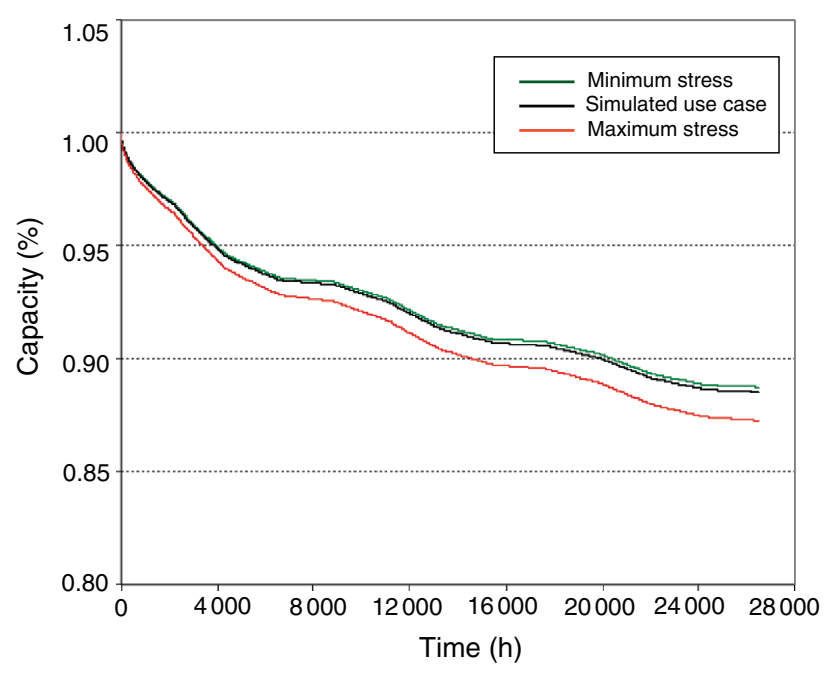

Figure 11

Evaluation of a battery capacity fade on a HEV.
The influence of the ambient temperature, which has been considered variable according to the seasons is observable in Figure 11, the steepest part of the curves corresponding to the hottest summer season.

In this example, a three-year operation of the vehicle, in an intensive way, will lead to a capacity fade under $15 \%$ which is quite low and do not lead to any noticeable effects on vehicle fuel economy and dynamic performances in our simulations.

This difficulty in accessing battery-ageing effect on HEV charge sustaining vehicle behavior is confirmed by vehicle end of life testing carried out in the US these past years within the Freedom Car program [19]. The results highlighted the fact that, even after $250000 \mathrm{~km}$ covered, a Prius NiMH pack had lost a large amount of its capacity but was still able to provide pulse power and the vehicle did not show any noticeable increase in fuel consumption. Indeed, in the CS HEV case the internal combustion engine can be operated in order to balance any modification in the way the ESS may behave.

One could notice that this vehicle simulation have been performed with a somehow oversized ESS, especially regarding its SOC window, which is maintained below $30 \%$ as it is generally the case for such applications. The application of the method described may enable to size the ESS much smaller, then cheaper, smaller and lighter, while securing the fact that it will last the expected life in operation.

\section{CONCLUSION AND FURTHER WORK}

In the frame of the SIMSTOCK program, which has now ended, very interesting results in the field of ESS ageing have been obtained. The main results are:

- the empirical model developed in this paper represents the capacity ageing due to the lithium losses as a function of current, temperature, Ah throughput and SOC variation;

- temperature is the predominant effect, before SOC variation, Ah throughput and current;

- without stress, a possible capacity recovery is revealed in the ageing representation;

- ageing estimation cannot be assessed by taking into account only the operating solicitations (cycling) but should considered also the calendar ageing;

- time, rather than cumulated $\mathrm{Ah}$, should be the variable to represent ageing.

The battery ageing model was implemented in a simulation platform to represent the effect of battery ageing on fuel consumption of an hybrid vehicle.

The approach developed within the SIMSTOCK project seems promising; more investigations have to be conducted in order to validate the accuracy on a larger domain. The modeling method has been set up in order to be compatible with the results of the SIMCAL program, which focuses on the calendar ageing, reinforcing then the coherent approach of the partners.

The partners of the SIMSTOCK/SIMCAL network are willing to continue their collaboration setting up a 
future program that may be launched in 2012 with the following main aims:

- reinforce the aptitude of the mathematical formulation to take into account the cycling - calendar coupling for wider experimental conditions, especially regarding temperature effects;

- define experimental protocols that use of current pattern that would be closer to actual use of ESS observed in vehicles;

- take into consideration the request of the program final users (Renault, PSA, Valeo) towards more energetic battery cells that will enable PHEV and EV cases to be taken into account;

- take into consideration the non-homogeneity of the numerous cells constituting the battery pack, especially considering their initial capacity and internal resistance and the way these parameters will evolve during the ageing process.

\section{ACKNOWLEDGMENTS}

From the corresponding author to all the SIMSTOCK/ SIMCAL network partners who have participated:

- BATSCAP: O. Caumont,

- CEA: B. Crouzevialle, A. Delaille, J. Lejosne, S. Mailley, S. Grolleau,

-EDF: L. Jamy,

- EIGSI: F. Duclaud, A. Mieze, A. Guignard,

- IFPEN: F. Badin, J. Bernard, R. Revel, S. Zinola,

- IMS: H. Henry, J.M. Vinassa,O. Briat, H. Sawadogo,

- IFSTTAR (INRETS LTE): S. Pélissier, N. Peyrol,

- IFSTTAR: (INRETS LTN): J. Kauv,

A. De Bernardinis,

- LEC: C. Forgez, G. Friedrich,

- LMS-Imagine: J. Hafsaoui, F. Sellier,

- LRCS: C. Delacourt, M. Kassem, W. Liu, M. Morcrette,

- MTA Cluster: C. Adès,

- PSA Peugeot-Citroën: M. Capelle, D. Porcellato,

T. Prenant,

- Renault: P. Gyan,

- SAFT: S. Bourlot,

- Valeo: D. Benchetrite, M. Ouattara-Brigaudet,

- ADEME: S. Biscaglia.

The authors wish also to thank the French ADEME for their active support in these researches.

\section{REFERENCES}

1 Vetter J., Novák P., Wagner M.R., Veit C., Möller K.-C., Besenhard J.O., Winter M., Wohlfahrt-Mehrens M.,
Vogler C. (2005) Ageing mechanisms in lithium-ion batteries, J. Power Sources 147(1-2), 269-281.

2 Aurbach D., Zinigrad E., Cohen Y., Teller H. (2002) A short review of failure mechanisms of lithium metal and lithiated graphite anodes in liquid electrolyte solutions, Solid State Ionics 148(3-4), 405-416.

3 Zhang D., Haran B.S., Durairajan A., White R.E., Podrazhansky Y., Popov B.N. (2000) Studies on capacity fade of lithium-ion batteries, J. Power Sources 91(2), 122-129.

4 Belt J.R., Ho C.D., Motloch C.G., Miller T.J., Habib M. A., Duong T.Q. (2005) The effect of temperature on capacity and power in cycled Lithium-ion batteries, J. Power Sources 142, 354.

5 Gaillac L. (2008) Accelerated Testing of Advanced Battery Technologies in PHEV Applications, World Electric Vehicle J. 2, 2, 83-92.

6 Conte V., Bloom I.D., Morita K., Ikeya T., Belt J.R. (2010) Ageing Testing Procedures on Lithium Batteries in an International Collaboration Context: Mario Conte, ENEA Italy, Fiorentino, EVS-25 World Congress, Shenzhen, China, 5-9 Nov.

7 Francfort J. (2006) Hybrid Electric Vehicle End-of-Life Testing On Honda Insights, Honda Gen I Civics and Toyota Gen I Priuses, Technical report, INL/EXT-06-01262, Francfort J., Karner D., Harkins R., Tardiolo J., Idaho National Laboratory, USA, Feb.

8 Badin F., Jeanneret B., Trigui R., Harel F., Jullien A., Hannebique M., Van Berten M., Metkemeijer R., Mayer D., Smaha M., Verdier L., Beretta J., Porcellato M., Parmentier M., Durand M., D'Ussel L., Bariand M., Biscaglia S. (2000) SIVTHEC, a research program to evaluate high power batteries ageing in actual use, 17th International Electric Vehicle Symposium, EVS-17, Montreal Canada, 15-18 Oct.

9 Badin F. (2009) Modelling of On-board Energy Storage System ageing, The French SIMSTOCK research network, International Electric Vehicle Symposium and Exposition, EVS24, Stavanger, Norway, 13-16 May.

10 Liu W., Delacourt C., Forgez C., Pélissier S. (2011) Study of graphite/NCA Li-ion Cell Degradation During Accelerated Aging Tests - Data Analysis of the SIMSTOCK Project, Vehicle Power and Propulsion Conference, VPPC 2011, Chicago, USA, 6-9 Sept.

11 Bernard J., Revel R. (2011) The French SIMCAL research network for modeling of Energy Storage System calendar ageing in EVs and HEVs - First Results, Advanced Automotive Battery Conference, AABC Poster 2011, Pasadena, California, 24-28 Jan.

12 Gyan P. (2011) SIMSTOCK/SIMCAL: French national collaborative projects on usage and calendar battery ageing, 4th International Congress on Automotive Battery Technology, Wiesbaden, 9-11 May.

13 Kuhn E., Forgez C., Lagonotte P., Friedrich G. (2006) Modelling Ni-mH battery using Cauer and Foster structures, J. Power Sources 158, 2, 1490-1497.

14 Hafsaoui J., Scordia J., Sellier F., Liu W., Delacourt C., Aubret P. (2010) Development of an electrochemical battery model and its parameters identification tool, SAE Society of Automotive Engineers World Congress, Yokohama, Japan, May.

15 Hafsaoui J., Sellier F. (2010) Electrochemical model and its parameters identification tool for the follow up of batteries 
ageing, EVS-25 World Congress, Shenzhen, China, 5-9 Nov.

16 Smith K., Markel T., Kim G.-H. (2010) A Pesaran, Design of Electric Drive Vehicle Batteries for Long Life and Low Cost, IEEE 2010 Workshop on Accelerated Stress Testing and Reliability, Denver, Colorado, 6-8 Oct., IEEE NREL/ PR-5400-48933.

17 Dudezert D. (2009) Fatigue des batteries Li-ion dans le cadre d'une utilisation véhicule électrique, Impact des conditions d'utilisations sur le vieillissement, PhD thesis, Université Paris Sud.
18 Badey Q. (2012) Étude des mécanismes et modélisation du vieillissement des batteries lithium-ion dans le cadre d'un usage automobile, PhD thesis, Université Paris Sud.

19 FREEDOMCAR, INEEL (2005) Advanced Technology Development Program for Lithium-Ion Batteries, Battery Technology Life Verification Test Manual.

Final manuscript received in January 2013

Published online in April 2013

Permission to make digital or hard copies of part or all of this work for personal or classroom use is granted without fee provided that copies are not made or distributed for profit or commercial advantage and that copies bear this notice and the full citation on the first page. Copyrights for components of this work owned by others than IFP Energies nouvelles must be honored. Abstracting with credit is permitted. To copy otherwise, to republish, to post on servers, or to redistribute to lists, requires prior specific permission and/or a fee: Request permission from Information Mission, IFP Energies nouvelles, fax. +331475270 96, or revueogst@ifpen.fr. 